\title{
Circulating Tumor Cells in Neuroblastoma
}

\author{
Nöroblastomada Dolaşan Tümör Hücreleri
}

\author{
Mili Jain ${ }^{1}$, Ashutosh Kumarr ${ }^{1}$, Sanjay Mishra ${ }^{1}$, Nishant Verma², Madhu Mati Goel ${ }^{1}$ \\ ${ }^{1}$ King George's Medical University, Department of Pathology, Uttar Pradesh, India \\ ${ }^{2}$ King George's Medical University, Department of Pediatrics, Uttar Pradesh, India
}

\section{To the Editor,}

A 2-year-old girl presented with fever, hepatomegaly, and progressively increasing proptosis of the right eye for 1 month. Abdominal ultrasound revealed a well-defined multi-lobulated predominantly hyperechoic mass lesion of $10.9 \times 2.5 \times 6.1 \mathrm{~cm}$ with a few foci of coarse calcification and small cystic areas arising from the right suprarenal region. The lesion was inferiorly compressing the renal parenchyma; however, the interface was well maintained. Medially it was crossing the midline and encasing the aorta and its branches. The features were of neuroblastoma. The diagnosis was confirmed by TruCut biopsy from the suprarenal mass showing small round blue cells with salt and pepper chromatin. Immunohistochemistry was positive for synaptophysin. Non-contrast computerized tomography scanning of the head and orbit revealed a right retro-orbital mass with specks of calcification. The peripheral blood smears showed a few clusters and rosettes of circulating neuroblastoma cells. The bone marrow aspirate smears showed extensive infiltration by neuroblastoma cells dispersed singly, in clusters as well as in rosettes with central neuropils (Figure 1). The patient was categorized as stage IV as per the International Neuroblastoma Staging System.

Neuroblastoma is the most common extracranial solid tumor in children. The mean age of presentation is 18 months and the majority of patients $(90 \%)$ are diagnosed by 5 years of age [1]. The adrenal gland is the most common primary site. Approximately $75 \%$ of children have metastases to regional lymph nodes, bone marrow, cortical bones, the orbit, the liver, and skin at the time of diagnosis. The histology shows primitive neuroblasts with variable degrees of differentiation to Schwann cells and ganglion cells. Homer-Wright rosettes, i.e. neuroblasts surrounding a tangle of neuropils, are seen. Infants may present with blue-red cutaneous masses, referred to as blueberry muffin baby. The differential diagnosis includes alveolar rhabdomyosarcoma (ARMS), Ewing's sarcoma/primitive neuroectodermal tumor (PNET), and lymphoma. ARMS cells are

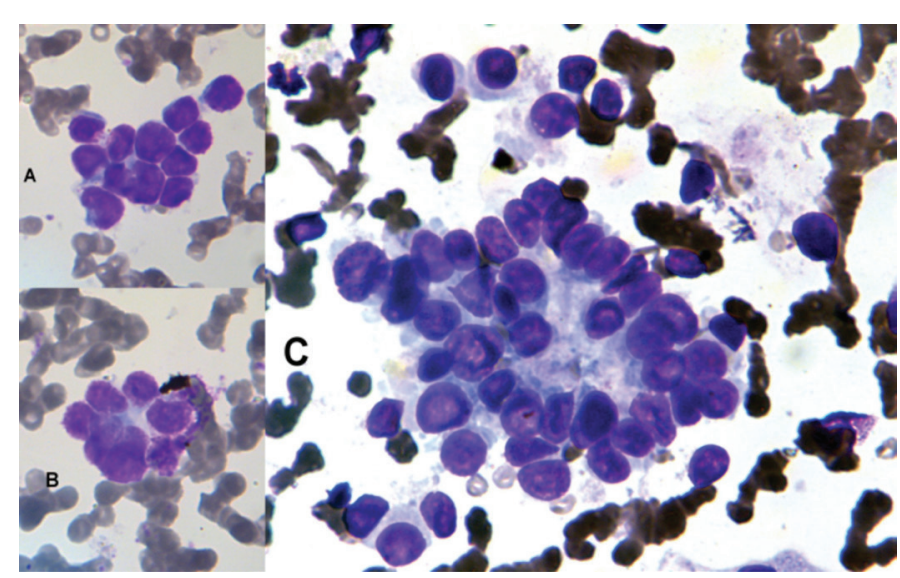

Figure 1. Leishman staining. A, B) Peripheral blood smear (630 ${ }^{x}$ showing neuroblastoma tumor cell cluster with nuclear molding and rosette-like arrangement. C) Bone marrow smear (400x) showing Homer-Wright rosette with neuroblasts surrounding central neuropil.

more pleomorphic with abundant cytoplasm and are positive for myogenic markers (desmin, myogenin). Ewing's sarcoma/ PNET patients are usually older; cells show finely stippled chromatin- and glycogen-filled cytoplasm, with expression of CD99. Neuroblastoma may clinically mimic acute leukemia [2]. These cells can be differentiated from blasts by expression of synaptophysin or neuron-specific enolase. The blasts are positive for leukocyte common antigen (LCA/CD45). Catecholamine metabolites homovanillic acid and vanillylmandelic acid are elevated in serum and urine in approximately 95\% of patients. Metastatic disease can be evaluated using iodine123-metaiodobenzylguanidine (123-I-MIBG) scanning. N-MYC amplification is associated with poor prognosis. Morphologically identifiable circulating tumor cells (CTCs) are a rare finding [3]. Positive CTCs are associated with poor prognosis [4].

Keywords: Neuroblastoma, Circulating tumor cells, Metastasis

Anahtar Sözcükler: Nöroblastoma, Dolaşan tümör hücreleri, Metastaz 
Conflict of Interest: The authors of this paper have no conflicts of interest, including specific financial interests, relationships, and/or affiliations relevant to the subject matter or materials included.

\section{References}

1. Brodeur G, Hogarty M, Bagatell R, Mosse YP, Maris JM Neuroblastoma. In: Pizzo P, Poplack D, (eds). Principles and Practice of Pediatric Oncology. Philadelphia, Lippincott Williams \& Wilkins, 2016.
2. Gökçe $M$, Aytaç $S$, Ünal Ş, Altan I, Gümrük F, Çetin M. Acute megakaryoblastic leukemia with $\mathrm{t}(1 ; 22)$ mimicking neuroblastoma in an infant. Turk J Hematol 2015;32:64-67.

3. Moodley V, Pool R. Circulating neuroblastoma cells in peripheral blood. Br J Haematol 2003;123:2.

4. Kuroda T, Morikawa N, Matsuoka K, Fujino A, Honna T, Nakagawa A, Kumagai $M$, Masaki $H$, Saeki M. Prognostic significance of circulating tumor cells and bone marrow micrometastasis in advanced neuroblastoma. J Pediatr Surg 2008;43:2182-2185.

\title{
Megakaryocytic Emperipolesis Associated with Thrombocytopenia: Causative or Coincidence?
}

\section{Trombositopeni ile Birlikte Megakaryositik Emperipolez: Nedensel veya Tesadüf?}

\author{
Manu Goyal $^{1}$, Sreeja Thandilath Thekkelakayil ${ }^{2}$, Anurag Gupta ${ }^{2,3}$ \\ ${ }^{1}$ AmPath Hyderabad Hospital, Clinics of Hematopathology and Molecular Hematopathology, Telangana, India \\ ${ }^{2}$ AmPath Hyderabad Hospital, Clinic of Hematopathology, Telangana, India \\ ${ }^{3}$ AmPath Hyderabad Hospital, Clinic of Cytogenetics, Telangana, India
}

\section{To the Editor,}

Phagocytosis, emperipolesis, and entosis are physiological and pathological phenomena characterized by the engulfment of one cell into another cell [1]. Emperipolesis is defined as active penetration of one cell by another, which remains intact [2]. Emperipolesis differs from phagocytosis in that an engulfed cell exists temporarily within another cell and with an intact normal structure, while in phagocytosis, the engulfed cell is destroyed by the proteolytic action of lysosomal enzymes [1,2]. Entosis is a non-apoptotic cell death mechanism that occurs in cell populations deprived of matrix attachment $[3,4]$.

A 31-year-old male presented with severe headache to the emergency department. He was afebrile without any organomegaly or neurological deficit. An urgent computed tomography scan of the brain showed subarachnoid hemorrhage. Complete blood counts revealed hemoglobin of $80 \mathrm{~g} / \mathrm{L}$, leukocyte count of $4.9 \times 10^{9} / \mathrm{L}$, platelet count of $5 \times 10^{9} / \mathrm{L}$, and a few giant platelets on peripheral smear. Prothrombin time, activated partial thromboplastin time, and fibrinogen were within the normal ranges. Bone marrow evaluation performed to assess the cause of severe thrombocytopenia showed normal erythropoiesis and myelopoiesis with increased megakaryocytes. These megakaryocytes showed neutrophils

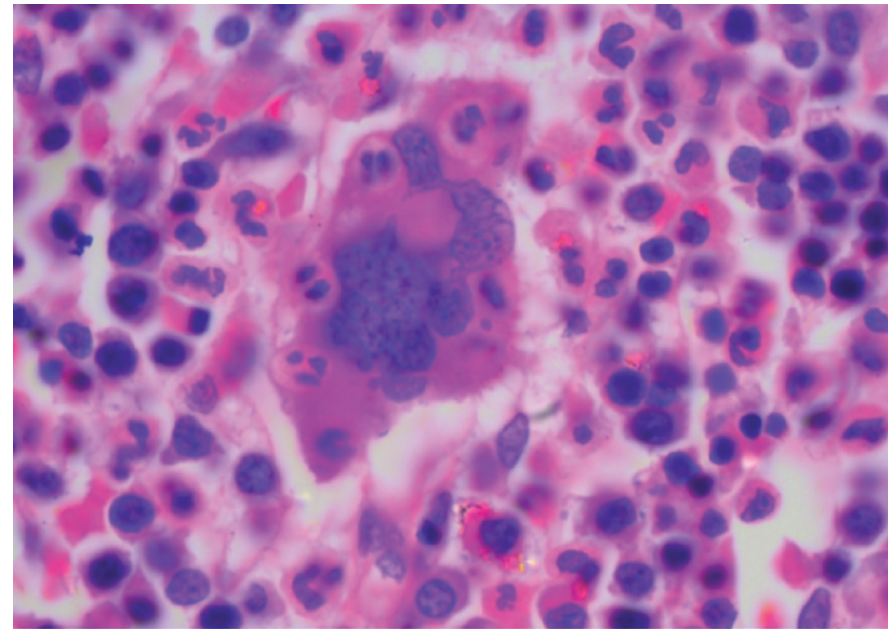

Figure 1. Photomicrograph of the trephine biopsy shows megakaryocytic emperipolesis containing neutrophils (hematoxylin and eosin stain, original magnification 630x).

with marked emperipolesis (Figure 1). There was no evidence of malignancy or infiltrate. A working diagnosis of immunemediated thrombocytopenia was issued and the patient was treated with steroids and intravenous immunoglobulins. In view of the marked thrombocytopenia and hemorrhagic complications, the patient was transfused with multiple units of single-donor platelets. Despite aggressive medical management, 